\title{
Extensive cauda equina tuberculomas: Mimicking ependymoma
}

\author{
Ramakrishna Narra', Suseel Kumar Kamaraju ${ }^{2}$ \\ From ${ }^{1}$ Professor, Department of Radiology, Katuri Medical College, Guntur, Andhra Pradesh, India, ${ }^{2}$ Professor, Department of Radiology, Katuri \\ Medical College, Guntur, Andhra Pradesh, India
}

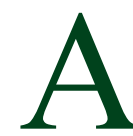

4-year-old male child presented to our hospital with a history of fever, generalized weakness, back pain, weakness of both the lower limbs, and stiffness with urinary retention since month. However, symptoms were exaggerated from the past days. On examination, bilateral lower limbs power was $4 / 5$, exaggerated deep tendon reflexes, loss of sensation below L2, and Babinski sign was positive.

An MRI of spine was performed under anesthesia. On T2W images (Fig. 1a), multiple conglomerate ring lesions with isointense rim and hyperintense center were noted in the distal spinal cord with extensive adjacent spinal cord edema extending in the visualized portion of dorsolumar spinal cord with expansion of the spinal cord in the conus region. Some of the ring lesions showed hypointense signals in the center representing possible caseation. On contrast, lesions showed uniform thick ring/rim enhancement, with a typical "conglomerate" pattern of distribution (Fig. 1b and c).

The result of tuberculin test was indeterminate and CSFPCR was positive for mycobacterium tuberculosis. Surgery was performed and laminectomy was done at L1, L2 vertebra and a median myelotomy was performed and biopsy taken after subtotal resection of the lesion. Pathological examination of the lesion revealed multiple epithelioid cell granulomas with Langerhans and giant cells. Large areas of caseous necrosis were seen and necrotic material. Diagnosis of tuberculosis was confirmed and the patient was treated with steroids for reduction of edema, and ATT was started for the residual lesions. Unfortunately, after 5 days, the patient expired.

The incidence of intramedullary spinal cord tuberculomas is rare and reported as approximately 2 in 100,000 cases of all tuberculosis. The incidence of tubercular abscess is even rarer [1]. To the best of our knowledge, review of cases in literature showed either a single or very few lesions, however, such extensive intramedullary conglomerate tuberculomas are not reported. Review of literature showed most of the cases reported

\section{Access this article online}

Received - 26 September 2020

Initial Review - 11 October 2020

Accepted - 13 October 2020

DOI: $10.32677 /$ IJCR.2020.v06.i10.020
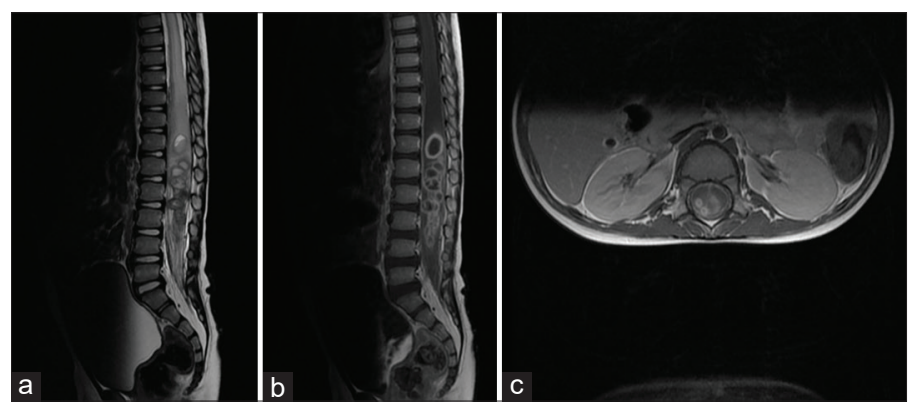

Figure 1: (a) Sagittal T2W MRI showing multiple ring-like isointense lesions in lumbar cord and conus medullaris with edema extending in the visualized portion of dorsal cord. (b) Sagittal contrast-enhanced T1W MRI showing typical ring-enhancing conglomerate lesions in the visualized lumbar spinal cord and conus medullaris with cord expansion. (c) Axial T1W contrast MRI at lumbar cord level showing ring-enhancing lesion within the lumbar cord

with thoracic cord being most common location followed by cervical cord and lumbar cord [2]. Our case showed extensive tuberculomas in lumbar spinal cord and cauda equina.

Differential diagnosis includes primary intramedullary spinal cord tumors such as cord ependymoma and astrocytoma [3] which are excluded in this case given clinical background and confirmed biopsy reports.

\section{REFERENCES}

1. Devi BI, Chandra S, Mongia S, Chandramouli BA, Sastry KV, Shankar SK. Spinal intramedullary tuberculoma and abscess: A rare cause of paraparesis. Neurol India 2002;50:494-6.

2. Citow JS, Ammirati M. Intramedullary tuberculoma of the spinal cord: Case report. Neurosurgery 1994;35:327-30.

3. Gupta VK, Sharma BS, Khosla VK. Intramedullary tuberculoma: Report of two cases with MRI findings. Surg Neurol 1995;44:241-4.

Funding: None; Conflicts of Interest: None Stated.

How to cite this article: Narra R, Kamaraju SK. Extensive cauda equina tuberculomas: Mimicking ependymoma. Indian $\mathrm{J}$ Case Reports. 2020; 6(10):605

Correspondence to: Dr. Ramakrishna Narra, Department of Radiology, Katuri Medical College, Guntur, Andhra Pradesh, India. E-mail: narra.ramki29@gmail.com

(C) 2020 Creative Commons Attribution-NonCommercial 4.0 International License (CC BY-NC-ND 4.0). 